\title{
The application of Principal Component Analysis Algorithm to Identification of Risk Factors in PFI of Construction of Small Towns
}

\author{
Rong Song \\ Shaanxi Institute of International Trade\& Commerce College, Xian Yang 710026, China \\ songrong2008@126.com
}

Keywords: Principal Component Analysis, establishment of small towns, risk estimation, PFI.

\begin{abstract}
In order to extract vital factors for the establishment of small town, PCA is introduced there. In this paper, the risk estimation of four small town in Shan' xi are taken as analysis data. As result shown, the policy, regulation and financial are the principal components in all the factors, and the policy is the most important one. And the result may be worth considering as making establishment plan.
\end{abstract}

\section{Introduction}

Private Finance Initiative (PFI) is a financing model, aiming to mobilizing private capital for better construction, and promote economic development. In developing the plan formulation, risk control is very important. There are many kinds of risk factors, which is not conducive to a comprehensive control and assurance; but there is a certain link between them, you can select from important factors, in order to facilitate the development of the plan. Principal component analysis (PCA) is a major factor algorithm, and it is widely used in many field [1,3]. Therefore this method will be used in the risk assessment, and to provide a reference for the development direction of small town.

\section{Illustration of PFI}

PFI means' Private Finance Initiative'[4], was translated into 'Private financing actively' in our country, is the BOT (Build Operate Transfer) and then the optimization and innovation of public project financing mode, put forward by the British government in 1992. The most important difference between the traditional BOT and PFI project, the government no longer buy project, but the purchasing service. PFI is department according to the social demand for infrastructure, construction project is put forward, through the bidding, construction and run by the private sector a license to do so, and in the concession period (usually for 30 years or so) at the end of the will to operate the project by intact, without obligation to repay the government, while the private sector from government departments or from accept service charge to recover the cost of project financing. Broadly speaking, this model project launched by the government, by the developers in project construction, operation, and provide services according to the regulations of the beforehand, users pay by use of the service.

\section{Principle of Principal Component Analysis (PCA)}

Principal component analysis (PCA) is a statistical analysis of the principal contradiction grasp of things [5].It can be resolved from diverse things out the main factors, revealing the essence of things, simplifying complex problems [1]. The principal component analysis is first proposedby Hotelling in 1933, and its purpose is to calculate the principal components projection high-dimensional data to lower-dimensional space. The new mapping space by a linear combination of the original data variable composition, thereby greatly reducing the dimension of the projection space, but also because the projection space statistical feature vectors orthogonal to each other, so eliminating the 
correlation between variables, and the complexity of the original Process Analysis has been greatly simplified.The calculation process is shown in fig.1, and is as follows:

(1). Select the sample matrix composition $X_{n, m}$, test samples $X_{n, 1}, \mathrm{n}$ is the number of feature dimensions, N samples;

(2). Calculate the covariance matrix $S_{n, n}$;

(3).Calculate the eigenvalues $\lambda_{1} \geq \lambda_{2} \geq \cdots \geq \lambda_{n}$ and eigenvectors $C_{n, n}$ of $S_{n, n}$;

(4).Select pre-m column directly $C_{n, n}$ to constitutes $C_{n, m}$ according tothe contribution rate

(5).The main component $X_{m, N}=C_{n, n}\left(X_{n, N}-\overline{X_{n, N}}\right)$ of the sample is calculated.

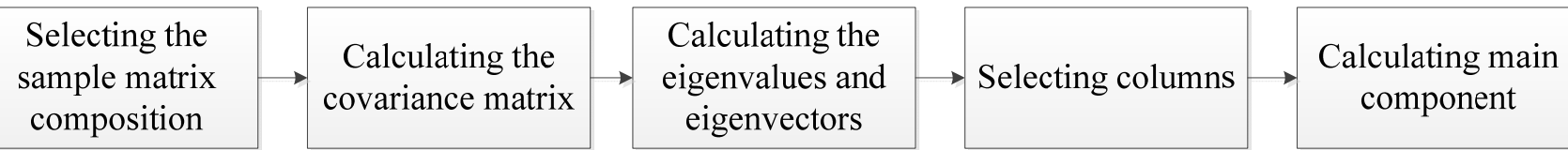

Fig.1 the calculation process of PCA

\section{Experiment and Analysis}

Table. 1 The original data-1

\begin{tabular}{ccccccc}
\hline $\begin{array}{c}\text { Evaluation } \\
\text { Index }\end{array}$ & Policy & Regulations & Financial & Environment & Feasibility & $\begin{array}{c}\text { The design } \\
\text { level }\end{array}$ \\
1 & 0.7701 & 0.6402 & 0.5042 & 0.4281 & 0.5394 & 0.6691 \\
2 & 0.7925 & 0.7901 & 0.6237 & 0.6934 & 0.6935 & 0.6109 \\
3 & 0.8239 & 0.8167 & 0.7788 & 0.7207 & 0.7468 & 0.6769 \\
4 & 0.7854 & 0.6926 & 0.5744 & 0.6456 & 0.5737 & 0.5958 \\
\hline
\end{tabular}

Table. 2 The original data-2

\begin{tabular}{ccccccc}
\hline $\begin{array}{c}\text { Evaluation } \\
\text { Index }\end{array}$ & $\begin{array}{c}\text { Completion } \\
\text { Risk }\end{array}$ & $\begin{array}{c}\text { Low } \\
\text { Income }\end{array}$ & $\begin{array}{c}\text { Credit } \\
\text { Risk }\end{array}$ & $\begin{array}{c}\text { Maintenance } \\
\text { Cost }\end{array}$ & Experience & $\begin{array}{c}\text { Responsibility } \\
\text { Distribution }\end{array}$ \\
1 & 0.5678 & 0.5124 & 0.5468 & 0.4352 & 0.4494 & 0.4602 \\
2 & 0.6842 & 0.4970 & 0.5034 & 0.4402 & 0.5018 & 0.4254 \\
3 & 0.7423 & 0.5501 & 0.4435 & 0.4501 & 0.4730 & 0.5012 \\
4 & 0.5972 & 0.4994 & 0.4860 & 0.5020 & 0.4910 & 0.5758 \\
\hline
\end{tabular}

According to the risk factors listed above, the following order YongShou, dry county, Li Quan, Jingyang example for quantitative analysis. Develop a questionnaire to collect data by PCA evaluation methods importance of risk factors is evaluated. The questionnaire is divided into three parts. The first section includes background questions responders personal and organizational information. The second part is a general question about PFI project. The third part is about the PFI project risk based on direct experience responders. 600 questionnaires distributed, $61 \%$ return. The Cronbach A method is used to calculateof questionnaire indicators for each variable property inspection. Cronbach A value of environmental risks and project risks in line with the minimum 
standards is 0.160 , Cronbach A value of other risks is 0.157 , which can be accepted. Therefore, the final data is considered to be effective, and can be carried out subsequent analysis. Since this is the main risk factor of importance of investment projects, so the overall evaluation of the project discussed in this article do not do too much.

According to 12 evaluation factors listed in Table 1 of the relevant circumstances expert scoring four regions.table. 1 and table. 2 are the original data. Fig. 2 shows the calculation result. As can be seen from fig.2, it can be known, the policy, regulation and financial are the principal components in all the factors, and the policy, whose rate is $80 \%$, is the most vital one.

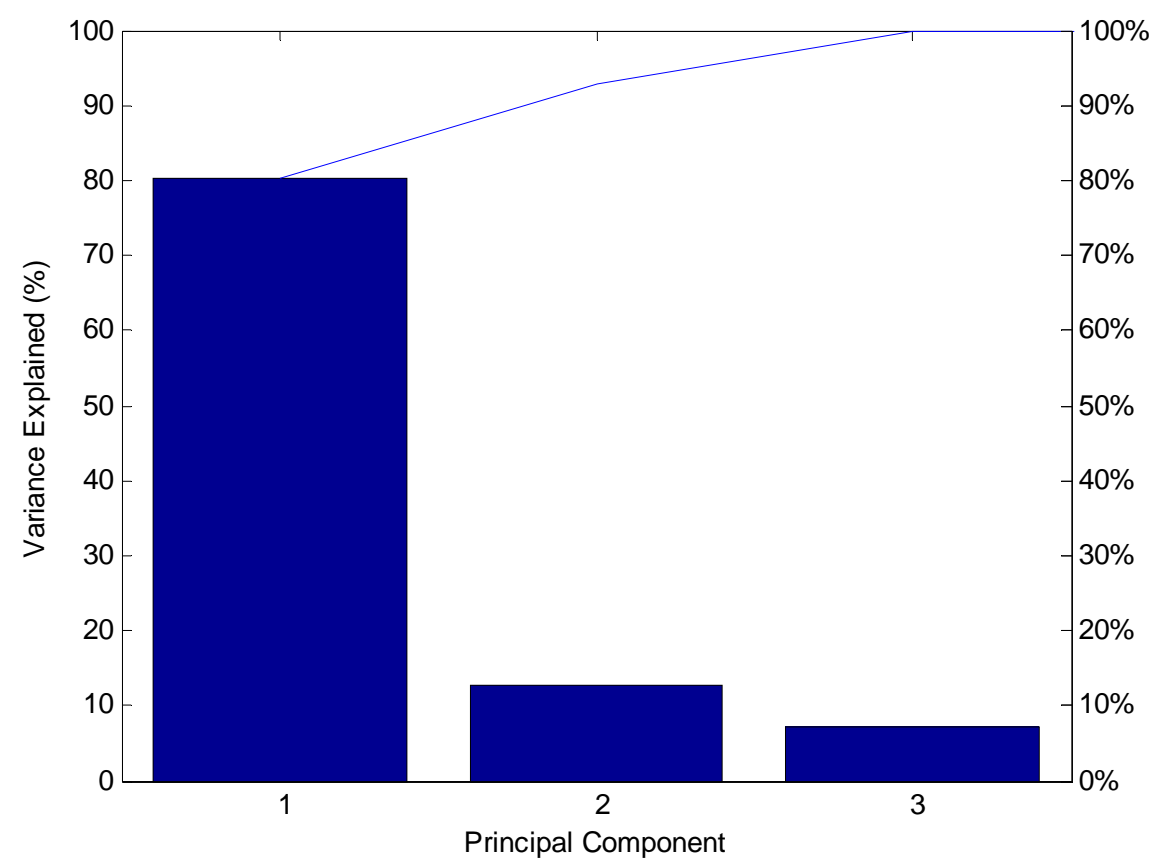

Fig.2 the principal components

\section{Conclusion}

In order to extract vital factors for the establishment of small town, PCA is introduced there. At first, the brief introduction of PFI is illustration. Secondly, the theory and the calculation process of PCA are presented. And then the risk estimation of four small town in Shan' xi are taken as analysis data. And the principal components are extract from all 12 factors. And the result may be worth considering as making establishment plan.

\section{Acknowledgments:}

This work is supported by the Project Foundation of Shaanxi Province Education Department (NO. 2013JK0169).

\section{References}

[1]Moore B. Principal component analysis in linear systems: Controllability, observability, and model reduction [J]. Automatic Control, IEEE Transactions on, 1981, 26(1): 17-32.

[2]Gabriel K R. The biplot graphic display of matrices with application to principal component analysis [J]. Biometrika, 1971, 58(3): 453-467.

[3]Baldi P, Hornik K. Neural networks and principal component analysis: Learning from examples without local minima [J]. Neural networks, 1989, 2(1): 53-58. 
[4] Kramer M A. Nonlinear principal component analysis using autoassociative neural networks [J]. AIChE journal, 1991, 37(2): 233-243.

[5] Friston K J, Frith C D, Liddle P F, et al. Functional connectivity: the principal-component analysis of large (PET) data sets[J]. Journal of cerebral blood flow and metabolism, 1993, 13: 5-5.

[6] Dong D, McAvoy T J. Nonlinear principal component analysis-based on principal curves and neural networks [J]. Computers \& Chemical Engineering, 1996, 20(1): 65-78.

[7]Gaffney D, Pollock A M, Price D, et al. The private finance initiative: PFI in the NHS -is there an economic case? [J]. BMJ: British Medical Journal, 1999, 319(7202): 116.

[8] Britain G. Private Opportunity, public benefit: progressing the private finance initiative [M]. Ministry of Defence, 1995.

[9] Akintoye A, Hardcastle C, Beck M, et al. Achieving best value in private finance initiative project procurement [J]. Construction Management and Economics, 2003, 21(5): 461-470.

[10]Wold S, Esbensen K, Geladi P. Principal component analysis [J]. Chemometrics and intelligent laboratory systems, 1987, 2(1): 37-52. 